\title{
Interference with the pacemakers of two workers at electricity substations
}

\author{
G S BUTROUS, ${ }^{1}$ R S BEXTON, ${ }^{1}$ D G BARTON, ${ }^{2}$ J C MALE,${ }^{3}$ AND A J CAMM ${ }^{1}$
}

From the Department of Cardiology, ${ }^{1}$ St Bartholomew's Hospital, West Smithfield, London EC1, Medical Branch, ${ }^{2}$ Central Electricity Generating Board, London EC4, and Central Electricity Research Laboratories, ${ }^{3}$ Leatherhead, Surrey, UK

ABSTRACT Pacemaker function was tested in two electricity substation workers exposed to high tension electric fields. High intensity electric fields induced reversion to the interference mode, producing in one case competitive rhythm and in the other inappropriately slow pacing which resulted in asymptomatic pauses of up to $2.5 \mathrm{~s}$. A suit designed to shield the body from the effects of high intensity electric fields was tried and proved to be effective in protecting the pacemaker, allowing it to function normally in the substations.

The effects of many environmental hazards on the functioning of implanted pacemakers is largely unknown. The rapidly advancing technology of cardiac pacemakers, increasing their versatility but at the same time their complexity, may well increase their sensitivity to external hazards. Under experimental conditions, high tension power frequency electric fields have been shown to affect some pacemakers adversely ${ }^{1-5}$ and we report here on two Central Electricity Generating Board (CEGB) employees with implanted pacemakers who worked in high tension substations. The behaviour of the pacemakers in the patients' everyday working environment is documented and possible protective measures are discussed.

\section{Case reports}

CASE 1

A 32 year old electrical engineer who works in a $275 / 132 \mathrm{kV}$ substation, which is a part of the transmission/distribution system in north London, has had ankylosing spondylitis for many years. Recently, severe intermittent sinus bradycardia was discovered for the treatment of which a Telectronics 174 programmable pacemaker was implanted in the right prepectoral region. He made an uneventful recovery after implantation.

On returning to his previous employment he observed an abnormal thumping sensation in the

Received 21 August 1982

Accepted 8 November 1982 chest whenever he went to certain areas of the substation near high voltage conductors. This observation was reported to his occupational medical adviser and electrocardiographic surveillance was performed at work using a telemetric system to be described elsewhere. ${ }^{6}$

During monitoring, the pacemaker reverted to the interference mode (fig 1) when the patient was standing on an earthed aluminium plate in a high intensity power frequency field sufficient in the circumstances to induce a corporeal current of $41 \mu \mathrm{A}$ or more (field strength $2.5 \mathrm{kV} / \mathrm{m}$ with the arms raised and $3.0 \mathrm{kV} / \mathrm{m}$ with the arms at the side). Reversion to interference mode was always associated with his reported symptoms. When the patient walked a few feet away to a region with a lower electric field, the pacemaker reverted to normal.

These observations were re-evaluated at the Central Electricity Research Laboratories (CERL) at Leatherhead, Surrey, where a facility for producing high intensity $50 \mathrm{~Hz}$ electric fields is available for research purposes. The patient stood on an earthed aluminium plate and the field strength was increased gradually from zero. The pacemaker reverted to interference mode when the field reached $2 \mathrm{kV} / \mathrm{m}$ (unperturbed value measured at $1.8 \mathrm{~m}$ above the ground), inducing a corporeal current of $25 \mu \mathrm{A}$ (fig 2).

\section{CASE 2}

A 57 year old electrical engineer whose duties include occasional visits to high voltage substations, was admitted to hospital for investigation of 


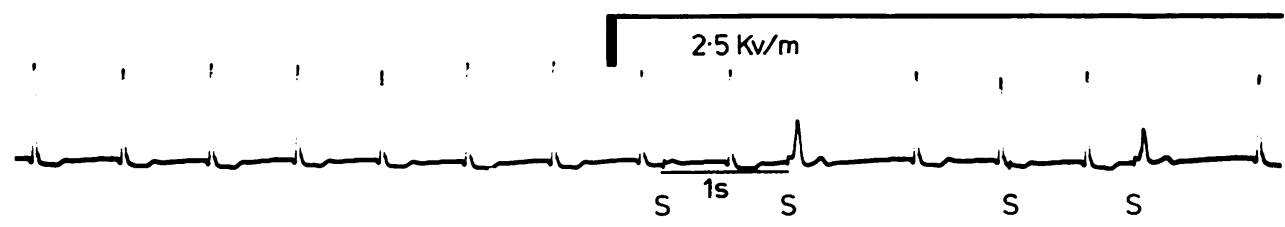

Fig 1 Reversion of pacemaker to interference mode when the patient (case 1) stood with raised arms in substation where an electrical field of $2.5 \mathrm{kV} / \mathrm{m}$ was encountered and a corporeal current of $41 \mu \mathrm{A}$ was induced. ( $S$ = pacing stimulus.)

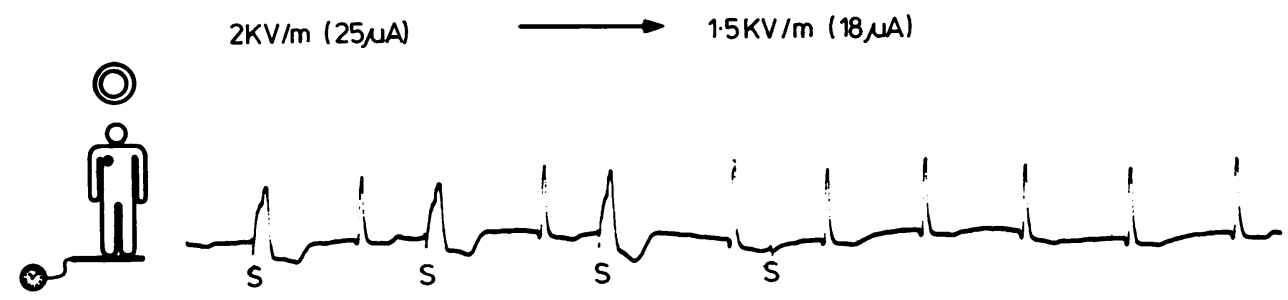

Fig 2 Reversion of pacemaker to interference mode in case 1 during exposure to a high intensity field at CERL. ( $S$ = pacing stimulus.)

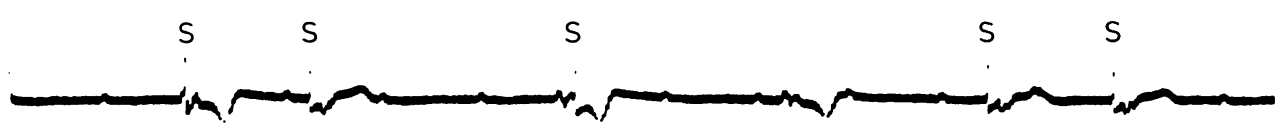

CG Cordis $334 \mathrm{~A}$ 迢 Field $15 \mathrm{KV} / \mathrm{m}$ current $194 \mu \mathrm{A}$

Fig 3 Irregular and slow pacing when case 2 was standing in a high intensity field $(15 \mathrm{kV} / \mathrm{m})$, which induced a body current of $194 \mu A$, at CERL. ( $S=$ pacing stimulus.)

episodes of syncope. He gave a one year history of dizzy spells occurring two or three times a day. In the two months before admission episodes of syncope had occurred on several occasions. Examination showed clinical evidence of aortic stenosis. During ambulatory ECG monitoring, episodes of first, second, and third degree heart block were recorded which correlated with the symptoms of dizziness. Implantation of a permanent pacemaker was therefore advised, and a Cordis 334A pulse generator was implanted in the left prepectoral region.

Before returning to work, the pacemaker was tested at CERL as described above. Exposure to high intensity fields produced pronounced changes in the functioning of the pacemaker, changes observed at field strengths above $13 \mathrm{kV} / \mathrm{m}$ with the patient standing with both arms at his side. Exposure produced inappropriately slow irregular pacing (with pacemaker impulse intervals up to $2.5 \mathrm{~s}$ ) lasting for a few seconds and followed by regular pacing at a rate of $40-50 \mathrm{ppm}$ (fig 3).
The pacemaker reverted to normal immediately the electric field was switched off. These findings were consistently reproduced when the patient was retested in a typical working environment in a 400 / $275 \mathrm{kV}$ substation.

\section{Discussion}

Electromagnetic interference is now recognised as a cause of pacemaker malfunction. The modern demand pulse generator with its potentially high sensitivity and the almost universal use of unipolar electrodes have increased the risk of malfunction induced by electromagnetic interference arising from either internal-that is, muscle contractionor external sources such as current leakage from household appliances. All pacemaker manufacturers have now incorporated a reversion circuit in the pulse generator to overcome this hazard. In the presence of interference this circuit reverts the pulse generator to a fixed rate pacing mode (interference 
mode).

Fixed rate pacing may, however, produce a competitive rhythm which can cause an uncomfortable sensation in the chest (as in case 1) or even initiate dangerous arrhythmias, ${ }^{78}$ particularly in the presence of a diseased myocardium or therapeutic agents such as digoxin. These arrhythmias are much less common than theoretically anticipated, however. ${ }^{9}$

The behaviour of the pacemaker in the presence of electromagnetic interference in the first reported case is not entirely unexpected. In previous experiments Telectronics pulse generators have been found to revert to interference mode with corporeal currents of less than $120 \mu \mathrm{A}^{10}$. In this patient, however, the minimum amount of current required for reversion was exceptionally low. Currents of this magnitude may be induced by the electric fields present both in substations and in the vicinity of overhead cables.

It is difficult to account for the discrepancy between the minimum current required to revert the pacemaker at CERL and that at the substation (25 $\mu \mathrm{A} v 42 \mu \mathrm{A})$. There are several possible explanations. Firstly, the electric field produced at CERL -may have been more uniform and vertical than in the substation, where multiple sources of electric fields from several directions may have given rise to a different corporeal current distribution. In our experience the distribution of current within the body plays a crucial part in determining the minimum reversion condition..$^{10}$ Nevertheless, reversion occurred at the same values of field and body current in the laboratory when the high voltage electrode was set well to one side of the patient rather than directly overhead. A second possible factor is that the high voltage electrode at CERL carried no load current, whereas substantial currents were present at the substation. In the substation the measured magnetic field at reversion was $60 \mathrm{mG}(\mathrm{rms})$. The precise effect of such a contribution to the electromagnetic environment is difficult to determine because of the complex distribution of the electric fields and currents. Jenkins and Woody have found that $60 \mathrm{~Hz}$ magnetic fields above $1.1 \mathrm{G}$ may affect pacemaker function. ${ }^{2}$ Another explanation for the discrepancy is that on both occasions there were differences in the electrostatic shielding of the telemetry box and electrodes attached to the patients. The shielding foil might provide a short-circuit path over the body surface (SJ Meldrum, unpublished observations) although subsequent tests showed that typical differences in the shielding arrangements had no discernible effect on the minimum reversion current.

The behaviour of the pacemaker in the second case cannot be explained on the basis of reversion to interference mode but is presumably due either to intermittent oversensing of the extraneous electromagnetic signals or to oversensing of a combination of cardiac and external interference signals. Similar malfunctioning has been observed with other manufacturers' pulse generators ${ }^{10}$ and must be considered as a potentially dangerous hazard of high tension power frequency fields in pacemaker dependent patients. In this patient malfunction occurred only in a high intensity field (greater than $13 \mathrm{kV} / \mathrm{m}$ ), encountered in few areas in a high tension substation. Similar units implanted in other patients, however, may behave in the same manner at much lower field intensities.

It is essential to protect pacemaker users working in the vicinity of exposed high voltage conductors. A "Faraday suit" to shield the pacemaker from the effect of high tension fields has been tried and has proved effective, although it may sometimes be inconvenient to wear. The implantation of a pulse generator that is not affected by this form of interference in a patient at risk would eliminate the need for protection by a cumbersome suit. Recently one pacemaker manufacturer (Medtronic) has incorporated a circuit in their pulse generators that adjusts the sensitivity of the sensing amplifier so that regular interference signals are ignored. Patients with this type of pacemaker have been investigated in the presence of fields up to $20 \mathrm{kV} / \mathrm{m}$ producing corporeal currents of greater than $300 \mu \mathrm{A}$ and there was no effect on the sensing and pacing function of the pacemaker. ${ }^{5}$

Clearly, both implanting physicians and occupational medical officers should be aware of the potential environmental risks to pacemaker wearers and of possible solutions to these problems. Careful choice of pacemaker, local protective shielding, or modification of the working environment may be necessary to overcome these difficulties.

\section{Appendix}

\section{WORKER PROTECTION: A SOLUTION}

When a pacemaker that is sensitive to the effect of high intensity fields has already been implanted in a patient at risk of encountering such fields some form of protection must be sought. Several types of electrically conducting protective suits were tested both at CERL (fig 4) and at a $400 / 275 \mathrm{kV}$ substation. These suits were essentially whole body garments originally developed for personnel working in contact with live, high tension, transmission lines. From the investigations the following observations became apparent:

(1) It is essential that the suit should be of one 


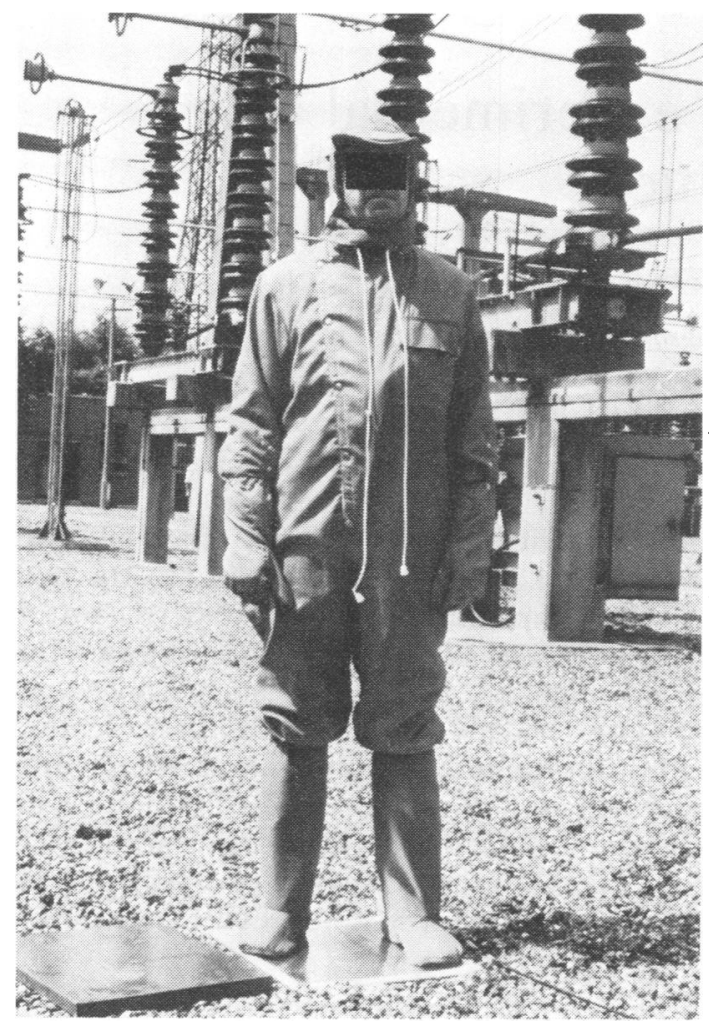

Fig 4 Protective suit found to be most convenient for protection of pacemaker, worn by worker during test in $400 / 275 k V$ substation.

piece with an integral head cover.

(2) It is essential that both the feet and the hands are protected because the displacement current may be picked up by these extremities, leading to internal voltage gradients that may be large enough to interfere with the pacemaker. Gloves and foot socklets should make good contact with the main part of the suit.

(3) It is advisable that the suit should be made of light material that is comfortable for the patient to wear and gives a full range of free movement.
We thank Dr Stuart Meldrum and Mr Robert Webber from the department of medical electronics at St Bartholomew's Hospital, London, and Mr Robert Hughes and his staff at CERL, Leatherhead, for their technical help. We are very grateful to $\operatorname{Dr} \mathbf{J} A$ Bonnell and Dr W T Norris for their encouragement and support.

This study was partly supported by the Central Electricity Generating Board. Dr G S Butrous is a recipient of a research grant from the University of Baghdad, Dr R S Bexton is supported by the British Heart Foundation, and Dr A J Camm is a Wellcome senior lecturer.

\section{Requests for reprints to Dr G S Butrous.}

\section{References}

' Furman S, Parker B, Krauthmer M, Escher DJW. The influence of electromagnetic environment on the performance of artificial cardiac pacemakers. Ann Thorac Surg 1968;6:90-5.

2 Jenkins BM, Woody JA. Cardiac pacemaker responses to power frequency signals. In: IEEE international symposium on electromagnetic compatibility, 1978. Institute of Electrical and Electronic Engineers, Inc 1978:273-7.

${ }^{3}$ Bridges JE, Frazier MJ, Hauser RG. The effect of $60 \mathrm{~Hz}$ electric fields and currents on implanted cardiac pacemakers. In: IEEE international symposium on the electromagnetic compatibility, 1978. Institute of Electrical and Electronic Engineers, Inc 1978:258-65.

4 Bridges JE, Frazier MJ. The effect of $60 \mathrm{~Hz}$ electric and magnetic fields on implanted cardiac pacemakers. Chicago; ITT Research Institute, 1979. (EPRI, EA-1174.)

${ }^{5}$ Butrous GS, Meldrum SJ, Barton DG, Male JC, Bonnell JA, Camm AJ. Effects of high-intensity power frequency electric fields on implanted modern multiprogrammable cardiac pacemakers. JR Soc Med 1982;75:327-31.

- Meldrum S, Butrous GS, Camm AJ. Electrocardiographic recording in high intensity electric fields. J Med Eng Technol (in press).

' Bilitch M, Cosby RS, Cafferky EA. Ventricular fibrillation and competitive pacing. N Engl J Med 1967;276:598-604.

8 Tavel ME, Fisch C. Repetitive ventricular arrhythmia resulting from artificial internal pacemaker. Circulation 1964;30:493500.

${ }^{9}$ El-Sherif N, Javier RP, Gann D, Waxman H, Samet P. Pacemaker electrocardiography. In: Samet P, El-Sherif N, eds. Cardiac pacing. 2nd ed. New York: Grune and Stratton, 1980:149-206.

${ }^{10}$ Butrous G, Male, J, Barton D, Nathan A, Camm J. The effect of high intensity power frequency fields on implanted cardiac pacemakers. PACE 1983;61:A-53. 